\title{
Sağlıkta Şiddetin Bir Başka Yüzü: Medya Etkisi
}

\section{Another Face of Violence in Healthcare: The Media Impact}

\author{
Kenan KAYA $^{1}$ (D) , Özgenur KÖKEN TOK ${ }^{2}$ (D)
}

${ }^{1}$ Çukurova Üniversitesi Tıp Fakültesi, Adli Tıp Anabilim Dalı, Adana, TÜRKiYE

2 TC Adli Tıp Kurumu, Osmaniye Adli Tıp Şube Müdürlüğü, Osmaniye, TÜRKiYE

öz.

Amaç: Medyada hatalı tıbbi uygulama iddiaları ve sağlık çalışanlarına yönelik şiddet içerikli haberlerin sürekli yayınlanması, haberlerin sunuluş şekli, sağlık çalışanlarını değersiz kılma çabası günümüzde sıkça karşılaştı̆̆ımız durumlardandır.

Materyal ve Metod: Çalışmamızda kitle iletişim araçlarının tıbbi uygulamalarla ilgili haberleri ele alış, hatalı tıbbi uygulama iddiaları ve sağlıkta şiddet hakkındaki haberleri aktarış şekillerini incelemek amacıyla ulusal gazetelerdeki ilgili haberler retrospektif incelenmiştir.

Bulgular: Haberlerin sunuluşunda; 'Kör bırakan inmale 4 milyon lirayı bulan tazminat', 'Mide küçültme ameliyatı iki çocuk babasının sonu oldu', 'Karın ağrısıyla hastaneye gitti, hayatı karardı', 'Sezaryen sırasında karnında bant unutuldu', 'Mide ameliyatında kalbini kestiler','Kırık kol için girdikleri hastanede cansız bedeniyle çıktılar', 'Doktora bayıltan dayak' gibi başlıklar kullanıııı̆ı̆ görülmüştür.

Sonuç: Hekimlere/sağlık çalışanlarına yönelik şiddette medyanın kışkırtıcı rol oynadığı, yapılan haberlerin sağ|ık çalışanlarına güvenilirliği zedelediği görülmektedir. Medya olması gereken sağlıklı atmosferi tüketen bir rol yerine hepimizin ihtiyacı olan temiz havayı koruyabilir, kirlenen havayı temizleyebilir.

Anahtar Kelimeler: Medya, Sağlıkta Şiddet, Tıbbi Uygulama Hatası

\section{Abstract}

Background: In the media, allegations of medical malpractice and violence in healthcare continuous publication of news of violence against healthcare professionals, the way the news are presented, and the effort to make healthcare professionals worthless are among the situations we encounter frequently today. Materials and Methods: In our study, the relevant news in national newspapers were analyzed retrospectively in order to examine the way in which the mass media deal with news related to medical practices, allegations of wrongful medical practice and news about violence in health.

Results: In the presentation of the news; It has been observed that headings such as, 'Compensation of 4 million lira for negligence that caused blindness',' Stomach reduction surgery caused the death of two children's sather', 'He went to the hospital with abdominal pain, his life was darkened', 'The band was forgotten in his abdomen during cesarean section', 'They cut his heart in stomach surgery', 'He went to the hospital for a broken arm, came out with his lifeless body', 'The doctor was fainting beating' etc.

Conclusion: It is observed that the media play a provocative role in violence against physicians/healthcare professionals and the news has damaged the reliability of healthcare professionals. Media can protect the clean air we all need and clean the polluted air instead of a role that consumes the healthy atmosphere that should be.

Key Words: Media, Violence In Healthcare, Medical Malpractice
Sorumlu Yazar/Corresponding Author

\section{Dr. Kenan KAYA}

Çukurova Üniversitesi Tıp Fakültesi Balcalı Hastanesi Adli Tıp Anabilim Dalı, Sinanpaşa Mh. Balcalı Hastanesi 01790 Sarıçam/Adana, TÜRKIYE

E-mail: k_kaya_71@hotmail.com

Geliş tarihi / Received: 09.04.2021

Kabul tarihi / Accepted: 24.06.2021

DOI: $10.35440 /$ hutfd. 912615

Çalışma, 1. Uluslararası 17. Ulusal Adli Bilimler Kongresi (12-15 Kasım,2020) 'nde sözel bildiri olarak sunulmuștur. 


\section{Giriş}

Sağlık, insanoğlunun var olduğundan bu yana en vazgeçilemez ihtiyacı ve insan yaşamı üzerinde etkili en önemli kavramların başında yer almaktadır. Birey, kendisinin ya da yakınının sağlığı ile ilgili bir tehlike söz konusu olduğunda buna hızlı ve etkili bir çare aramakta, bu amaçla sağlık kuruluşlarına başvurmaktadır. Ancak durum kimi zaman istediği gibi sonuçlanmadığında yaşadığı üzüntü ve hayal kırıklığı gerginliğe dönüşebilmekte, bunun sonucunda da kişi şiddeti kendinde hak olarak görebilmektedir. Medyada hatalı tıbbi uygulama iddiaları ve sağlık çalışanlarına yönelik şiddet içerikli haberlerin sürekli yayınlanması, haberlerin sunuluş şekli, sağıık çalışanlarını değersiz kılma çabası günümüzde sıkça karşılaştığımız durumlardandır. Özellikle sağlık çalışanlarına yönelik şiddet haberlerinin artması, sağlıkta şiddetin toplumsal bir sorun oluşu, vaka sayısı olarak azımsanmayacak derecede fazla oluşu ve bu konudaki haberlerin medyada olağan-sıradanmış gibi yansıtılması durumları konunun ele alınması gerektiğini göstermektedir. Bu tarz haberlerin sorumlu bir yayıncılık anlayışıyla, sansasyondan ve iddiadan uzak, objektif olarak verilmesi gerekirken, magazinsel veya üçüncü sayfa haberciliği boyutunda kurgulandığı görülmektedir. Ayrıca film ve dizilerde şiddetin bir çözüm aracı olarak sunulması da şiddet olaylarının meşrulaştırılmasına neden olmaktadır.

İletişim, esasında bir alıcı ve bir gönderici arasında gerçekleşen, karşılıklılık esasına dayanan bir olaydır (1). Bu çerçevede; medya ile dinleyiciler-izleyiciler arasındaki ilişki de toplumsal bir iletişim olayını içermektedir. Kitle iletişiminde son nokta ise hedef kitleyi etkilemektir. Habercilik anlamında geleneksel medyaya karşı internet medyasının bir fırsat, tehdit, avantaj ya da dezavantaj olup olmadığı konusu tartışılmakla birlikte hızla gelişen bilgisayar teknolojileri ve internetin sağladığı yeniliklerin habercilik faaliyetlerine yeni bir alan açmış olduğu görülmektedir. Günümüzde, insanlar ülke veya dünya gündemiyle ilgili haberlere, genellikle basılı bir gazete ile ulaşmaktansa internet siteleri veya haber siteleri üzerinden cep telefonu, sosyal medya uygulamaları ya da bilgisayarları aracılığıyla takip etmektedir (2). İnsanların bir olay nerede gerçekleşmiş olursa olsun bilgiye hemen ulaşabilmeleri faydalar sağlamakla birlikte, internette çokça kirlenmiş bilginin mevcut olması karışıklıklara sebep olmaktadır. Medya kişilerin bilgi, tavır, davranış ve duyguları üzerinde etki etme ve onları şekillendirme gücüne sahiptir. Sadece bireyler üzerinde değil, ayrıca toplumsal gruplar, organizasyonlar, kurumlar, yani kısacası bütün toplum ve kültür, medyanın etki alanı dâhilindedir. Aynı zamanda medya, çok etkin bir sosyalizasyon (toplumsallaştırma) ajanıdır (1). Genel anlamıyla sosyalizasyon, bireyin davranışlarının şekillenmesini, sahip olduğu ya da toplum tarafından kendisine verilen rolün ve bunların sonucunda sahip olunan statünün gerektirdiği davranış biçimlerini, toplumun ve diğer bireylerin kendisinden beklentilerini öğrenme sürecidir (1). Etkileşimler; sonucunda izleyici, dinleyici, okuyucu durumundaki kişileri küçük veya büyük çapta değiştirebilmektedir.
Kan ya da şiddet gördüğünde rahatsız olan, korkan, olumsuz duygusal tepkiler gösteren kişi, bu maruziyet tekrar ettikçe duyarsızlaşmakta, empati, sempati ve ilgisini yitirmektedir. Çok fazla şiddet içeriğine maruz kaldığında ise şiddetin artık yaygın, kabul edilebilir ve kaçınılmaz bir hal olduğunu düşünmeye başlamaktadır.

Medya, bilgiyi aktarırken bireylerin düşüncelerini ve davranışlarını şekillendirmektedir. Bu sebeple bir haber oluşturulurken, bunun verilip verilmeyeceğine ya da nasıl verileceğine medya etiği açısından dikkat edilmesi gerekmektedir. Ancak çoğu zaman reyting kaygısı, habere olan ilgiyi artırmak gibi amaçlarla, haber magazinleştirilmekte, haberde kullanılan sözlü/görsel dil ile haber içeriği popülerleştirilmektedir. Bir mağdur yaratma, olayı trajik hale getirme ve izleyeni duygusal olarak etkileme çabası güdülmektedir. Şiddet ifadeleri ve eylemleri; televizyonda, dizilerde, filmlerde, yarışma programlarında, dijital oyunlarda, çizgi filmlerde çokça yer almakta, haberlere eklenen video görüntüleri ile birlikte daha çarpıcı hale getirilmekte, böylelikle medya içeriklerinin izlenilirliğini/okunurluğunu arttırmak, haber değeri taşımasını da sağlamak amaçlanmaktadır (2). Bir haberde ya da ilanda başlık, metinden daha önemlidir. Çünkü olayın özetini verir, çoğunlukla çekiciliğini artırır ve okuyucuyu/ dinleyiciyi teşvik eder. Bu sayede kişinin haber metnine bakış açısını da yönlendirir. Çalışmamızda kitle iletişim araçlarının özellikle tıbbi uygulamalarla ilgili haberleri ele alış ve aktarış şekillerine değinilmesi, hatalı tıbbi uygulama iddiaları ve sağlıkta şiddet hakkındaki haberleri aktarış şekillerinin incelenmesi amaçlanmıştır.

\section{Materyal ve Metod}

Çalışmamızda, ulusal gazetelerin yaptığı sağlıkta şiddet, hatalı tıbbi uygulama iddiaları ile ilgili haber başlıkları ve içerikleri retrospektif olarak değerlendirilmiştir.

\section{Bulgular}

Çalışmamız kapsamında, incelenen ulusal yayın organlarında tıbbi uygulamalarla ilgili haberlerin sunuluş şekilleri, ulusal gazetelerin yaptığı konuyla ilgili haber başlıkları ve içerikleri incelendiğinde; 'Kör bırakan ihmale 4 milyon lirayı bulan tazminat', 'Mide küçültme ameliyatı iki çocuk babasının sonu oldu', 'Karın ağrısıyla hastaneye gitti, hayatı karardı', 'Sezaryen sırasında karnında bant unutuldu', 'Mide ameliyatında kalbini kestiler', 'Doktor tamamen yalan söylüyor', 'Kırık kol için girdikleri hastanede cansız bedeniyle çıktılar' gibi başlıklar kullanıldığı görülmüştür. Bu haberlerin içeriğine bakıldığında tamamen tek taraflı bakış açısı ile oluşturulmuş, hastaların doktorlar tarafından mağdur edildiğine inandırımaya çalışılan, kimi zaman tıbbi tanımlamalardan ve uygulamalardan bihaber, tamamen izleyicininokuyucunun ilgisini artırmak uğruna sağlık çalışanlarını değersizleştiren, itibarını zedeleyen söylemler kullanıldığı görülmüştür. Bu tarzda yapılan haberler içerisinde ' 7 aylık hamile doktorun karnına tekme', 'Sülale halinde doktora saldırdılar', 'Doktora bayıltan dayak', 'Silahla vurulan hastaya 
müdahale eden doktoru hastanelik ettiler', 'Uyanmayan oğlunu öldü sanınca doktoru sopayla dövdü', 'Antalya'da acil servis doktoruna demir çubuklarla saldırdılar'şeklinde başlıklarla şiddet uygulayanı güçlü olarak yansıtıp doktoru ve doktorluk mesleğini itibarsızlaştıran, şiddeti meşrulaştıran,değerleştiren, popüler tutan, sıradanlaştıran, kanıksatan ve bayağılaştıran söylemler, 'ilaç yazmadı diye doktora saldırdı', 'Ölüm haberi veren doktorun burnunu kırdılar', 'Ambulans önüne park etmeyin diye uyaran doktora saldırı', 'Salgın var maske takın diye uyaran doktora saldırdılar', 'Yanlış teşhis ettin dedi doktorun kolunu kırdı', 'Koronavirüslü dehşet!' "Bana bakmak zorundasınız" dedi, sağlıkçıları darp etti' gibi başlıklarla şiddeti gerekçelendirilerek herkesçe onaylanacak bir niteliğe kavuşturan (meşrulaştıran) söylemler, 'Hastanede darp iddiası', 'Kadınlar doktora saldırdı iddiası' şeklindeki başlıklarla saldırının okuyucuda şüphe uyandırmasını sağlayacak söylemler, 'Doktora şiddete devam', 'Yine doktora saldırı', 'Doktora şiddet önlenemiyor' gibi başlıklarla da şiddetin sürekliliğine vurgu yaparak aslında normal bir durummuş algısının oluşturulmasına yönelik söylemler yer aldığı görülmüştür. 'Saldırı anı kamerada' şeklinde yazılı metne iliştirilen video görüntüleri ile daha çarpıcı ve seyirlik olması amacıyla düzenlenen başlıklar sıklıkla medya haberlerinde karşımıza çıkmıştır. Aynı şekilde adeta saldırıyı onaylayacak şekilde 'Var ya, siz doktorları boşuna dövmüyorlar yani' diyerek çizerin eleştirmektense gülünçleştirme amacı güttüğü karikatürde de şiddeti uygulayanların haklı çıkarılmaya çalışıldığı düşünülmüştür (2).

\section{Tartışma}

Hekimlik, doğası gereği riskli bir meslektir, izin verilen riskin tıbbi karşılığı ise komplikasyondur. Bu şekilde kabul edilen normal sapmalar sebebiyle doğacak kötü sonuçlar, tek başına kusur sayılmaz, hekimi sorumlu kılmaz (3). Malpraktis ise kötü, hatalı uygulama anlamındadır $(4,5)$. Hekimin sorumluluğu ancak kusurlu uygulama hatasından dolayıdır. Medya'da hatalı tıbbi uygulama iddiaları üzerine yapılan haberlerde, iyi-kötü karşıtlığını oluşturacak şekilde kurgulamalar, hastanın tamamen doktor tarafından mağdur edildiği, çaresiz bırakıldığı şeklinde tek yönlü bir bakış sunar tarzda tutumlar, tıbbi uygulamalarda izin verilen risklerin yani komplikasyonların malpraktis gibi yansıtılması, hastanın bu konuda hakkını araması gerektiği konusunda yoğun söylemler sonucu doktorlara karşı güvene gölge düşmektedir. Güvensizlik ortamında ise sağlıklı bir sağlık hizmeti sunulamamakta, doktor-hasta arasında güven duygusu kalmayınca toplumda var olan şiddet, doktorları da hedef seçebilmektedir. Genele bakıldığında medya şirketleri; kârı en yüksekte tutma, daha çarpıcı manşetler oluşturabilme, izlenme/tıklanma sayılarını artırabilme uğruna sorumlu yayıncılık anlayışından vazgeçmemeli, içeriklerinde sansasyondan uzak, "sağııkı" bir sağlık haberciliği anlayışına bürünmelidir. Sürekli yinelenen, defalarca gösterilen görüntüler, anlatılan olaylar, insanlar üzerinde hayatla ilgili örnek modeller ve önyargılar oluşturmakta, davranışların şekillenmesinde rol oynamaktadır. Basın Meslek Illkeleri'nin 13'üncü maddesinde belirtilen "Şiddet ve zorbalığı özendirici, insani değerleri incitici yayın yapmaktan kaçınılır" ilkesine, Türkiye Gazetecileri Hak ve Sorumluluk Bildirgesi'nde yer alan gazeteci temel görevleri ve ilkeleri kapsamında "Gazeteci her türden şiddeti haklı gösterici, özendirici ve kışkırtıcı yayın yapmamaya özen gösterir" ilkesine her gazetecinin özen göstermesi gerekir (6-8). Incelenen haberler doğrultusunda, hekimlere/sağlık çalışanlarına yönelik şiddette medyanın kışkırtıcı rol oynadığı görülmektedir. Bu bağlamda, medya metinlerinin üretim süreçleri içerisinde yer alanların sosyal sağlık bilincinde hareket etmelerinin, sağlık iletişimi ve sağlık haberciliği eğitimi almalarının da bu tehlikeli ve sorunlu dilin düzeltilebilmesi açısından faydalı olacağını düşünmekteyiz. Medyada TV programlarında sağlık çalışanlarına şiddeti haklı gösteren, bu olayları gündelik suç olayları olarak haberleştiren ve haber bültenlerinde yeterli araştırma yapılmadan, bazen tıpla alakalı olan bilgilerin alelacele hazırlanan, aslında normal olan bir durumu yanlış bir olaymışçasına sunan, toplumsal ya da sistemsel sorunlara değinmek yerine olayın sadece görünen yüzüne, olayın taraflarına (çoğu zaman tek tarafına) odaklanan, sağlık kurumları ve çalışanlarını hedef gösteren içerikler yasaklanmalıdır. Haberlerde, içerik kadar beraberinde yayınlanan fotoğraflara da dikkat edilmeli, yasağa uymayan medya kuruluşlarına ciddi yaptırımlar uygulanmalı, haberler etik kurallar gözetilerek, dil dikkatli kullanılarak yayınlanmalıdır. Özellikle sağlık politikalarını belirleyen siyasetçiler, sağlıkta şiddeti kınayan ve sağlık çalışanlarının verdiği hizmetin önemine vurgu yapan söylemler geliştirmelidir. Sağlık çalışanlarına şiddet konusunda toplumsal duyarlılığı arttırabilmek için kamu spotları yapılmalı, etkin mücadele edebilmek için sağlık yöneticileri, meslek örgütleri ve sendikalar birlikte hareket etmeli ve ortak programlar yapmalı, sağlık çalışanlarının çalışma şartlarının zorluğu konusunda halkın farkındalığı artırılmalıdır. Şiddet uygulayanların caydırıcı cezalar alması sağlanmalı, verilen cezalar adli para cezasına çevrilmemelidir. Verilen cezaların farklı medya organları aracılı̆̆ıyla caydırıcılığı arttırılmalı, haber başlıklarında bu yaptırımlar ve cezalar şiddet eyleminden daha öncelikli yer almalıdır (9).

Tüm davranışlar gibi şiddetin de öğrenilen bir davranış olması göz önünde tutulmalıdır. Ayrıca şunu da eklemek gerekir ki, yalnızca şiddet içeriği anlamında değil de genel anlamda zararlı olabileceği tartışılan tüm medya içeriklerine karşı izleyici/okuyucuların eleştirel medya okuryazarı, kişilerin hasta veya sağıı hizmeti alan bireyler olarak hakları ve sorumluluklarının bilincinde birer sağlık okuryazarı olabilmeleri gerekmekte, buna yönelik politikalar ve eğitim çalışmalarının geliştirilmesi faydalı olacaktır. Belki de ancak bu şekilde, medya olması gereken sağlıklı atmosferi tüketmek yerine, hepimizin ihtiyacı olan temiz havayı koruyup, kirlenen havayı temizleyebilir, hepimiz için daha sağlıklı ve huzurlu bir dünya, biz sağlık çalışanları için daha güvenli bir çaıışma ortamı oluşturmaya katkı sağlayabilir. 
Etik Onam: Çalışma etik onam gerektirmemektedir.

\section{Yazar Katkıları:}

Konsept: K.K.; Ö.K.T.

Literatür Tarama: K.K.; Ö.K.T.

Tasarım: K.K.; Ö.K.T.

Veri toplama: K.K.; Ö.K.T.

Analiz ve yorum: K.K.; Ö.K.T.

Makale yazımı: K.K.; Ö.K.T.

Eleştirel incelenmesi: K.K.; Ö.K.T.

Çıkar Çatışması: Yazarlar çıkar çatışması olmadığını beyan eder.

Finansal Destek: Araştırma kapsamında herhangi bir kurum ya da kuruluştan finansal destek sağlanmamıştır.

\section{Kaynaklar}

1. Arslan DA. Medyanın Birey, Toplum Ve Kültür Üzerine Etkileri. Uluslararası İnsan Bilimleri Dergisi 2004; 1(1).

2. Durur EK. Medyada Şiddetin Bir Başka Yüzü: 'Doktora Saldırı Haberleri. Uluslararası Sağlık İletişimi Sempozyumu (23 Kasım 2017) Bildiri E-Kitabı, Ss. 75. PDF, 1. (2017).

3. Bilge YE, Geçim E.E. (Editörler) Medikolegal Düzlem Tıpta Uygulama Hataları. Ankara: Ofset Digital, 2012:19.

4. Keskinbora KH. Malpraktis Nedir? Komplikasyon Nedir? Önlemek İçin Neler Bilinmelidir?. Türkiye Klinikleri Adli TıpÖzel Konular, 2019; 5(2):30-44.

5. Türk Tabipleri Birliği Hekimlik Meslek Etiği Kuralları. Yayın Tarihi: 01.02.1999. https://www.ttb.org.tr/mevzuat/index. php?option=com_content $\&$ view=article\&id=65: heklmeslek-etkurallari\&catid=4:t\&Itemid=31. Erişim tarihi: 30.12.2020

6. Duğan Ö. Sağlıkta şiddet haberlerinin basına yansıması. Doktora Tezi. Konya: Selçuk Üniversitesi Sosyal Bilimleri Enstitüsü, 2015.

7. Basın Meslek ilkeleri, 28 Nisan 2009 https://www.cumhuriyet.com.tr/haber/basin-meslek-ilkeleri-58518. Erişim tarihi: 30.12 .2020

8. Türkiye Gazetecileri Hak ve Sorumluluk Bildirgesi, $17 \mathrm{Ni}-$ san 2019, https://www.tgc.org.tr/bildirgeler/t\%C3\%BCrkiye-gazetecilik-hak-ve-sorumluluk-bildirgesi.html. Erişim tarihi: 30.12.2020

9. Yılmaz K. Adana İlinde Sağıı Çalışanlarının Şiddete Uğrama Sıklığı Ve Sağlıkta Şiddet Konusundaki Düşünceleri. Uzmanlık Tezi. Adana: Çukurova Üniversitesi Tıp Fakültesi Adli Tıp Anabilim Dalı,2020. 